\title{
Percutaneous Trans-Mitral Commissurotomy in the Contemporary Era, Real Time Experience and a Retrospective Analysis
}

\author{
Wesam A. Alhejily, MD, FRCPC, FACP, FACC, FSCAI \\ Department of Medicine, Faculty of Medicine \\ King Abdulaziz University, Jeddah, Saudi Arabia
}

\section{Correspondence}

Dr. Wesam A. Alhejily

P.O. Box 80215, Jeddah 21589, Saudi Arabia

e.M: walhejily@kau.edu.sa

Submission: 16 Oct. 2015

Accepted: 23 Nov. 2015

\section{Citation}

Alhejily, WA. Percutaneous trans-mitral commissurotomy in the contemporary era, real time experience and a retrospective analysis. JKAU Med Sci 2016; 23 (1): 29-39. DOI: 10.4197/ Med. 23.1.5

\begin{abstract}
Rheumatic mitral stenosis is a rare disease nowadays. In the Kingdom of Saudi Arabia and at King Abdulaziz University Hospital, we still see annually a few cases of advanced cases of rheumatic mitral stenosis among adult patients requiring hospital admission and urgent interventional treatment. We opt to study retrospectively the clinical presentation, techniques, outcomes, complications, and predictors of mortality related to percutaneous balloon intervention in patients with symptomatic mitral stenosis who were treated at King Abdulaziz University Hospital between 2009 and 2015. Among 6536 adult admissions over a 6-year time period, there were 21 new cases of symptomatic, echo-confirmed mitral stenosis (3/1000); only 6 cases (28.6\%) were eligible for intervention. In the intervention group the mean age was 38; $83 \%$ were female; $50 \%$ Non-Saudi. In five (83\%) out of six cases balloon valvuloplasty had increased mitral valve area by $0.596 \pm 0.312$ and reduced the mean mitral valve gradient by $6 \pm 3.847$ ( $p=0.05$ and 0.012 respectively). The most important predictor of successful dilation to valve area above 1.5 was Wilkin's score. Two indirect deaths occurred in a 6-month follow-up period and were correlated to age of 45 and above with initial presentation of either stroke, or pulmonary hypertension (mean pulmonary artery pressure $>45$ ) and refractory heart failure.
\end{abstract}

\section{Keywords}

Percutaneous mitral balloon commissurotomy; Mitral stenosis; Rheumatic fever.

\section{Introduction}

$R$ heumatic fever remains to be the most common cause of acquired mitral valve stenosis in the developing countries ${ }^{[1]}$. In Saudi Arabia there is a significant decline in the incidence of acute rheumatic fever among children visiting the ER in at least two tertiary centers in the eastern and central regions between 1990 and $2011^{[2-5]}$, incidence had declined from $45 / 100,000$ to $12.5 / 100,000$, respectively, compared to $14 / 100,000$ in North America[6].

Valvulitis leading to mitral regurgitation is the early valvular manifestation of acute rheumatic fever affecting the mitral valve, Mitral stenosis results from the healing process that involves thickening, fibrosis, scar formation and shortening of the chordae, there are more predilection to the anetromedial and 
posterolateral commissures than any other part of the mitral valve leading to mitral commissural fusion, the pathognomonic sign of mitral stenosis; but with time any part can be involved. The duration of this process varies from one geographical area to another, based on the WHO Technical Report, the median time of developing mitral stenosis symptoms may take from 10-40 years in the developed regions while it may take shorter time in another epidemic areas with a mean of $3-5$ years ${ }^{[7,8]}$, it is estimated that $16 \%$ of patient with prior history of rheumatic fever will develop some degree of mitral stenosis during their lifetime ${ }^{[9]}$. Median survival rate after symptoms is 2.4-3.5 years if no intervention was done and the most common cause of death is heart failure, stroke and pulmonary embolism ${ }^{[10]}$.

TheAmerican HeartAssociation recentguidelines ${ }^{[11]}$ had shed light on the different stages through which mitral valve stenosis can progress before presenting with symptoms. Symptomatic patients with severe MS (mitral valve area $\leq 1.5 \mathrm{~cm}^{2}$, Stage D) and favorable valve morphology in the absence of left atrial thrombus or moderate-to-severe mitral regurgitation are (Class 1) indication for intervention. In asymptomatic patients it is debatable (Class 2 b) to intervene if there is a new onset atrial fibrillation or when exercise pulmonary capillary wedge pressure is elevated to $25 \mathrm{mmHg}$ or more. Two methods of interventions are known to date, both of which are aimed to split the fusion points of the anteromedial and posterolateral commissures or what is known as commissurotomy. The classic old one is open commissurotomy; this was substituted by percutaneous trans-mitral commissurotomy (PTMC) in 1984 when Dr. Inoue and his colleagues ${ }^{[12]}$ reported the first case series using a special balloon to cross through the mitral valve through a septal puncture window. In 1988 (Wilkins score) was adopted by most operators ${ }^{[13]}$; it predicts a higher success rate of this technique utilizing four genuine features of the mitral valve apparatus: thickening of the valve; mobility of the valve; degree of calcifications; and the involvement of subvalvular apparatus. Each part can get a score from 0 to 4 based on severity. In this paper we opt to study all cases of mitral stenosis that were eligible for PTMC and their outcomes in a single tertiary hospital in the city of Jeddah, Saudi Arabia.

\section{Methods}

After ethical approval to access patients' database was obtained from King Abdulaziz University - Research Ethics Committee, a retrospective analysis of all PTMC cases at King Abdulaziz University Hospital covering the period from 2009-2015 was performed. This analysis looked at patients' profile including demographics, clinical presentations, indications, hemodynamic and echocardiographic criteria pre PTMC. Evaluation of outcome related to interventions, limitations and complications were also addressed during and post PTMC in addition to follow up appointments. A chart and echocardiographic review was systemically done to identify patients. Follow up visits were also reviewed post intervention to assess improvement in functional status and response to therapy. Standardized echocardiographic study was done to patients with suspected or identifiable mitral stenosis at baseline and post PTMC at least once.

Pre PTMC protocol of assessing patient with mitral stenosis would include: History, physical examination, and Transthoracic Echocardiographic (TTE). The echo evaluation has to have multiple methods to assess severity of Rheumatic Mitral Stenosis (RMS) ${ }^{[14]}$ including planimetery, pressure half time, mean gradient, in addition to indirect indices of severity like mean pulmonary arterial pressure (MPAP) and Left atrial (LA) volume. Wilkins score is used to determine visibility of PTMC. Trans-esophageal echocardiogram (TEE) is performed to all patients to rule out left atrial appendage clot before proceeding with PTMC. There has to be no left atrial appendage clot and no significant MR. If patient's initial presentation was stroke due to mitral stenosis then anticoagulation is considered and PTMC is deferred ideally for 6 months and for a minimum of 4 weeks. Before considering PTMC a full neurological evaluation is made to assess longevity and functional status from stroke, a TEE is done ruling out residual thrombus, and bridging coagulation is planned. Further testing with Holter electrocardiogram, stress tests may be considered in certain patients.

After inclusions/exclusion criteria were applied to patients and informed consent obtained, balloon is prepped, flushed, sized and filled with diluted contrast, PTMC is typically performed under conscious sedation, and in a few occasions under general anesthesia when airway can't be protected (i.e., cardiogenic shock, stroke), sterilization and preparation of both groin area are undertaken in the normal fashion and with aseptic technique and standardized draping of the patients' body, local anesthetics are applied to both groin using $1 \%$ lidocaine of $10-15 \mathrm{ml}$ in the subcutaneous space, a 7 French femoral arterial sheath and a 5 French femoral venous sheaths are placed into the right and left femoral vein and artery respectively, a coronary 
angiogram is not routinely done to patients pre PTMC unless they have symptoms suggestive of coronary artery disease and in younger patients if they have risk factors. Left ventriculogram using a pigtail is done at base line with $15 \mathrm{ml}$ of contrast to assess mitral regurgitations using angiographic grading system, the pigtail is then pulled backwards to the ascending aorta to be used as a landmark for fluoroscopic guided septal puncture. Subsequently, right heart catheterization is performed with shunt runs pre and post procedure. Assumed Fick equation is used to determine cardiac output and to calculate mitral valve area. A standard septal puncture technique is finally performed using Mullins transseptal (Medtronic Dublin, Ireland) introducer sheaths and Brockenbrough curved needles (Medtronic Dublin, Ireland). After levo-phasic right atriogram with the guidance of biplane fluoroscopy and pigtail aiming away (posteriorly in the lateral view) (Fig. 1A) from the ascending aorta; the needle is advanced. In-patient under general anesthesia 2 and 3 Dimential Transthoracic Esophageal Echocardiogram (3 D TEE) is used to guide with septal puncture and balloon positioning without the need of atriogram (Fig. 1B). The Inoue balloon maximal size is calculated based
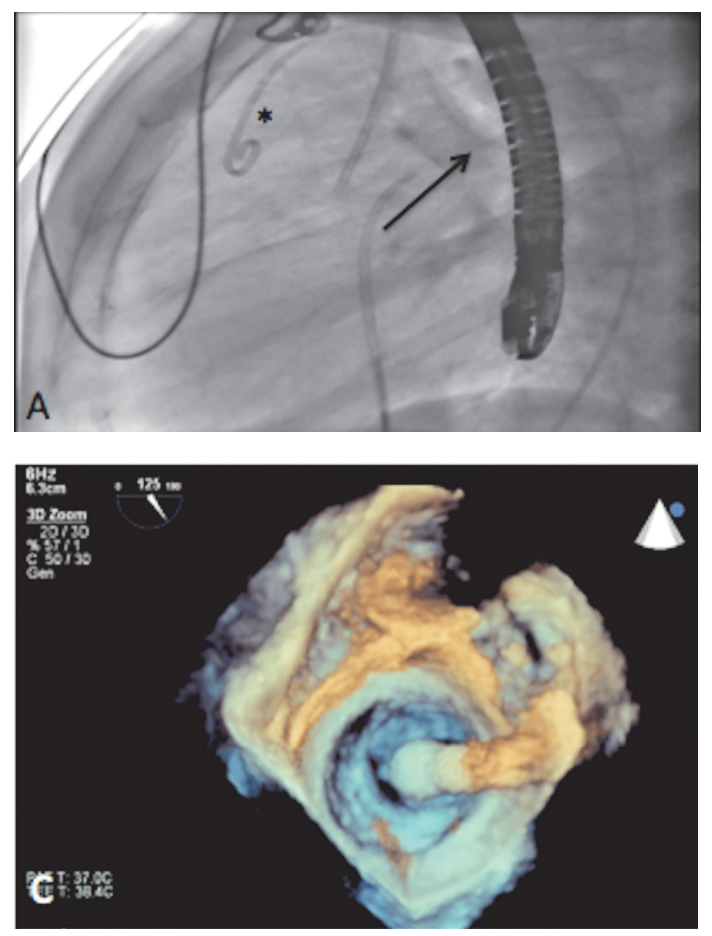

on patient height using the equation [Height/10]+10. Once septal puncture is done; confirmation of positioning is ensured using pressure tracing and blood gas saturation; then 5000 IU of intravenous heparin is given and the coiled-spring wire is placed into the left atrium. Finally, 18 French dilator is advanced once or twice over the wire through the septum before the balloon is used, several tricks are used to get the balloon across the valve particularly if the left atrium is dilated like the "pull and push" technique (retracting the stylet will push the balloon while advancing it will pull the balloon back), counter clock wise of the balloon with the stylet around the pulmonary veins and timing the movement of the balloon with diastole. $3 \mathrm{D}$ echocardiogram also helps guide the position of the balloon and crossing the stenotic mitral orifice in difficult cases (Fig. 1C). First dilation is typically done 4-mm lower than maximal balloon size (Fig. 1D, after each dilatation and after retracting the balloon to left atrium measurements of Mitral Valve Area (MVA) and gradient (superimposing LV and LA pressure tracing) are completed. An echocardiographic assessment is also performed between dilatation to assess need of more dilation and degree of mitral regurgitation,
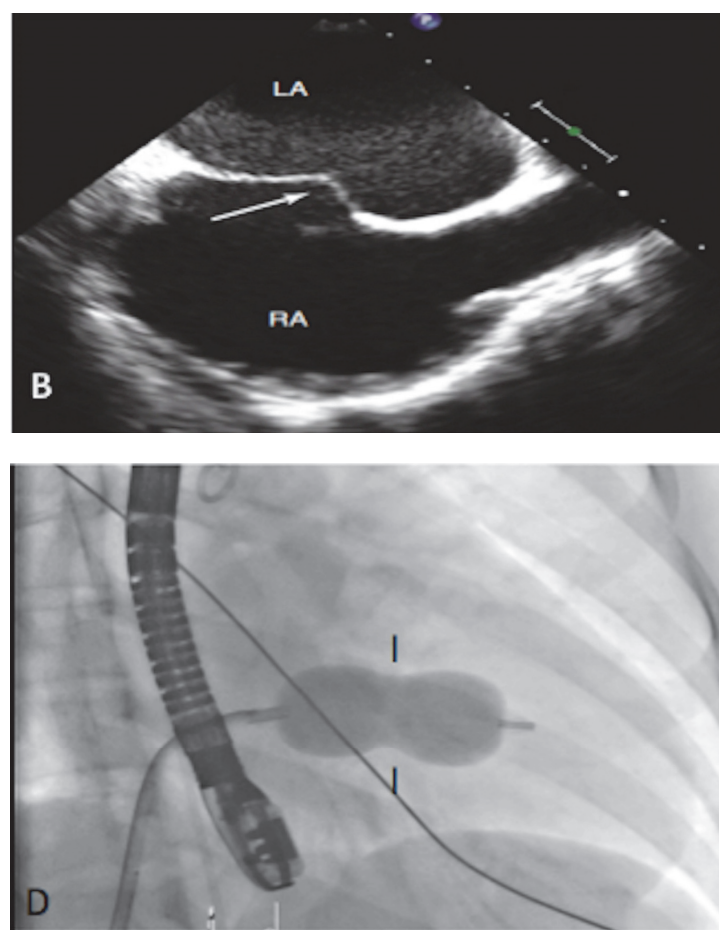

Figure 1. Echo-fluro guided septal puncture and balloon commissurotomy in mitral stenosis in Panel A: A lateral view shows a pig tail is placed into the aorta $\left(^{*}\right)$ to guide the septal puncture needle position, it should be posterior (black arrow) and inferior to the aorta, in B: Bicaval view with tenting (white arrow) of the septum before puncture is made. C: Demonstrates the use of 3D echo to confirm crossing of the mitral valve. Finally Inoue balloon is inflated at the mitral valve orifice outlined by the two black lines Panel (D). 
an increase in valve area to a reading equal to or above $1.5 \mathrm{~cm}^{2}$ and a drop in gradient by $50 \%$ are signs of successful PTMC, on the other hand if there is an increase in mitral regurgitation to $2+$ (moderate degree or more) at any stage of the intervention then procedure has to be omitted. After balloon is retracted out of the body an 18 French sheath is placed onto the right femoral vein, and removed later (after 1-2 hours) when clotting time is less than 160 seconds. Occasionally $50 \mathrm{cc}$ of protamine sulphate is given and both sheaths removed at the end of the procedure. Two nurses then apply manual pressure to each groin for 2030 minutes. No closure devices or figure of 8 sutures are to be used. Patients get admitted to telemetry where vitals and groin are to be checked every 1 hour then every 2-4 hours based on a standard protocol, routine blood tests are ensued as per protocol, a chest X-ray and an echocardiogram are done the following day and if no complications, patient is discharged after 24hour observation. In patients younger than 25 or with history of recurrent rheumatic fever consideration of benzathine penicillin monthly injection is undertaken and discussed with patient before discharge. Patients with prior history of stroke or atrial fibrillation will not be discharged until International Normalized Ratio (INR) is therapeutic using standard vitamin $\mathrm{K}$ antagonists and no novel oral anticoagulants (NOACs) are allowed. Patient has direct access to treating physicians and to cardiac services if any complications or new symptoms occur. Most patients are to be discharged on betablockers, diuretics and occasionally digoxin for rate

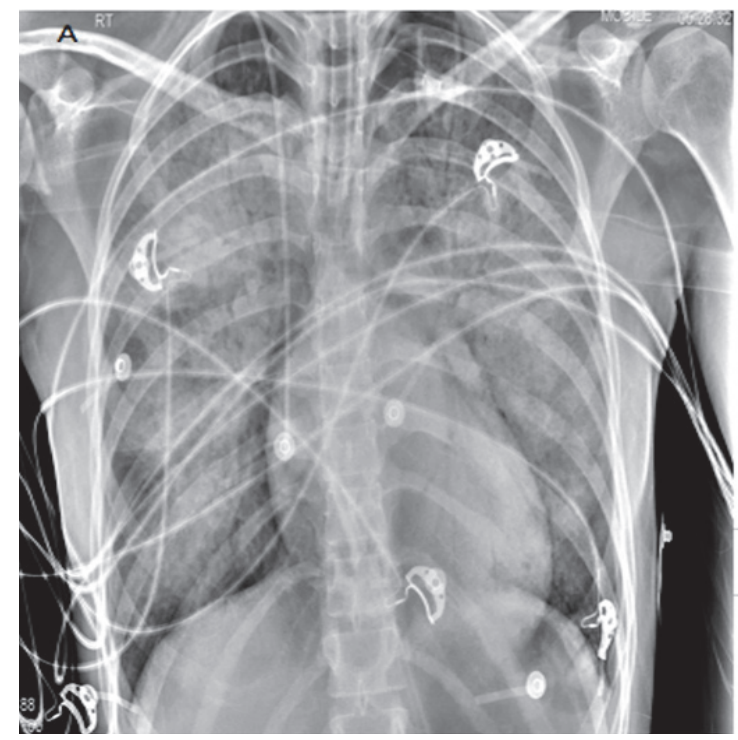

control. Follow-up appointment is scheduled at 1 month, and then 6 months followed by annual visits for echocardiographic assessment and clinical evaluation.

\section{Statistical Methods}

Pre- and post-PTMC mean valve area and gradient were reported to all patients, and a paired $t$ test statistics were applied using IBM SPSS Statistics for Windows, Version 20 (IBM Corp., Armonk, NY USA). 95\% confidence intervals were measured and results were reported as mean \pm Standard Deviation (SD).

\section{Results}

Despite a large volume and very busy cardiac services at King Abdulaziz University Hospital, we identified a total of 21 cases: most ( 70\%) underwent surgical interventions $(n=15)$ with valve replacement (mean age $=44,10$ were Females, $60 \%$ non-Saudi), the primary reasons for surgical interventions were heavily calcified vessel or the presence of more than moderate mitral regurgitation. Only 6 cases $(\sim 30 \%)$ were eligible for PTMC. Figure 1 shows still images of the protocol and technique used in echo-guided PTMC, these were done in the span of 6 years from September 2009 to September 2015. Females were predominant and represented more than $80 \%$ of these cases. $50 \%$ were Saudi from low socioeconomic stratum with a total of $50 \%$ having a documented or reported history of rheumatic fever during childhood; the non-Saudi

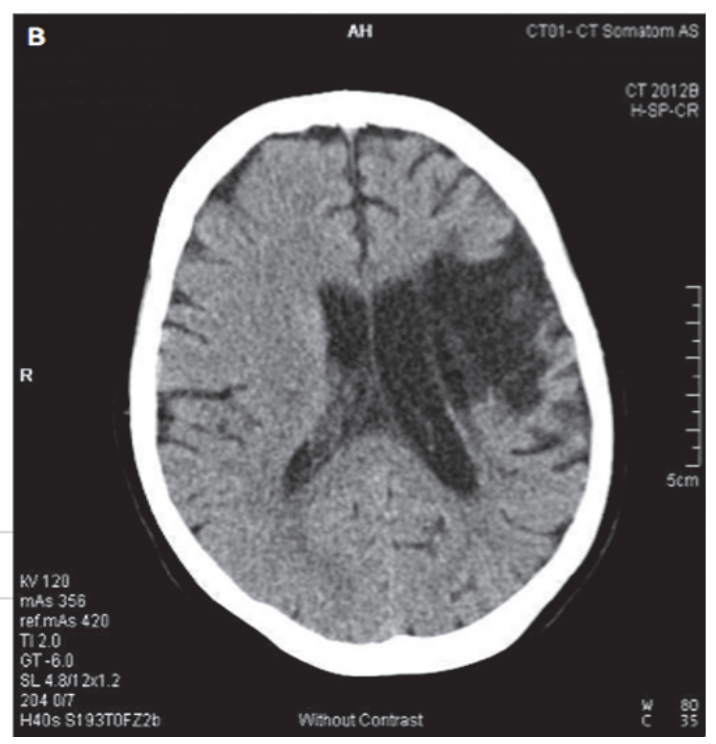

Figure 2. Two different clinical scenarios of bad outcomes in patients with symptomatic severe mitral stenosis: The right side panel (A) showed a chest X-ray of a patient presented with cardiogenic shock due to critical mitral stenosis, on the left hand (B) a CT scan of another patient demonstrated a large Fronto-parietal lobe stroke from thromboembolic occlusion of the left middle cerebral artery. 
group included three patients from Sudan, Afghanistan and Yemen they were expats working or visiting the Kingdom. $80 \%$ presented with symptoms of shortness of breath and exercise intolerance (New York Heart Association class 2-3) one with compensated heart failure (male patient) and one with critical RMS (MVA 0.78); Mitral Valve Gradient (MVG) of $24 \mathrm{mmHg}$; MPAP of $49 \mathrm{mmHg}$ presented with cardiogenic shock requiring intubation and ICU admission, her presenting symptoms were initially thought to be secondary to viral pneumonitis Middle Eastern Respiratory Syndrome-Corona virus (MERS-CoV) due to bilateral white-out lungs (Fig. 2A) but echocardiography and rapid improvement with diuretics helped reconcile the diagnosis of mitral stenosis. Finally one case was admitted as a large left Middle Cerebral Artery (MCA) stroke (Fig. 2B) and found to have severe mitral stenosis and paroxysmal atrial fibrillation. Table 1 shows demographic features of these cases. The mean age was 38 , MPAP was 45.3 and mean Wilkins score was 8.5 with minimal score of 5 and maximum of 13 . Table 2) shows the echocardiographic and hemodynamic features of mitral stenosis cases the success rate of opening the valve to a mean area of $1.5 \mathrm{~cm}^{2}$ was more than $80 \%$ when the score was 8 or less; $70 \%$ when 12 or less and $50 \%$ when score was 13 or more as depicted in the large arrows in (Fig. 3). Pre and post mitral valve areas have increased by $0.596 \pm 0.312$ statically it was borderline significant $p$ value 0.05 . On the other hand the mean valve gradient dropped by $6 \pm 3.847$ with a significant $p$ value 0.012 (Table 3, Figs. 3 and 4). One case was aborted due to septal hypertrophy, high degree of calcification led to failure of PTMC on the second attempt despite crossing the septum; case eventually was referred to surgery. Roughly 20-30 $\mathrm{ml}$ of contrast were used when fluoro-guided septal puncture is used, mean fluoro-time was 27 minutes with the shortest $15 \mathrm{~min}$ and longest 63 minutes, left atrial enlargement and crossing the mitral valve with the balloon was the most common reason for prolonged radiation time. Intracardiac echocardiogram (ICE) is not available in our center and we typically use 2 and 3 D TEE intra-procedurally for intubated patients and patients with septal anomalies or hypertrophy, it has been shown that ICE does shorten time of procedure and omits the need for contrast used. All procedures were tolerated very well, the most common complications, in order, were: mild hypotension at the end of the procedure with mean systolic pressure drop by 5 to 10 points from baseline; minor oozing at

Table 1. Demographic features, clinical presentations related to RMS patients who presented to King Abdulaziz University cardiac catheterization laboratory hospital form September 2009 to September 2015.

\begin{tabular}{|c|c|c|c|c|c|c|}
\hline No & $\begin{array}{c}\text { AGE } \\
\mathbf{M = 3 8}\end{array}$ & $\begin{array}{c}\text { Gender } \\
\mathbf{( 8 3} \% \mathbf{F})\end{array}$ & $\begin{array}{c}\text { Nationality } \\
\mathbf{5 0 \%} \text { Non-Saudi) }\end{array}$ & Clinical Presentation & $\begin{array}{c}\text { Success Rate } \\
\mathbf{8 3} \%)\end{array}$ & $\begin{array}{c}\text { Technique } \\
\text { of Septal Puncture }\end{array}$ \\
\hline 1 & 50 & $\mathrm{~F}$ & Non-Saudi & Dyspnea/Heart failure & Successful & FG \\
\hline 2 & 51 & F & Saudi & Stroke/ Atrial Fib & Successful & FG+TEE \\
\hline 3 & 21 & F & Saudi & Shock (ICU admission) & Successful & FG+TEE \\
\hline 4 & 48 & F & Saudi & Dyspnea NYHA 2 & Successful & FG \\
\hline 5 & 37 & F & Non-Saudi & Dyspnea NYAH 3 & Failed $^{\dagger}$ & FG \\
\hline 6 & 23 & M & Non-Saudi & Heart failure & Successful & \\
\hline
\end{tabular}

() Success rate is defined as an absolute increase in the valve area by at least 50\%. (") Procedure could not be performed due to failure of septal needle to puncture the inter-atrial septum (septal hypertrophy), patient referred for open valve commissurotomy. FG=fluoroscopy guided septal puncture. TEE=Transesophageal echocardiography.

Table 2. Echocardiographic and Hemodynamic features of mitral stenosis' cases.

\begin{tabular}{|c|c|c|c|c|c|c|c|}
\hline \multirow{2}{*}{ Patient \# } & \multirow{2}{*}{ MVA P1/2 } & \multirow{2}{*}{ MPAP } & \multicolumn{4}{|c|}{ Mitral Valve Score } & \multirow{2}{*}{ Total Score } \\
\cline { 4 - 7 } & & & T & M & Ca & Sub & \\
\hline 1 & 0.90 & 57 & 2 & 2 & 0 & 1 & 5 \\
\hline $2^{*}$ & 0.80 & 39 & 2 & 2 & 2 & 2 & 8 \\
\hline 3 & 0.78 & 49 & 2 & 2 & 2 & 3 & 11 \\
\hline 4 & 1.14 & $37.2^{\dagger}$ & 1 & 1 & 2 & 2 & 6 \\
\hline 5 & 0.90 & 47 & 4 & 4 & 3 & 2 & 13 \\
\hline 6 & 0.90 & 43 & 2 & 2 & 2 & 2 & 8 \\
\hline Mean & 1.07 & 45.3 & 1.8 & 1.8 & 1.3 & 2 & 8.5 \\
\hline
\end{tabular}

MVA=Mitral valve area; MPAP = Mean pulmonary arterial pressure, $P 1 / 2=$ Pressure half time, $T=$ Mitral valve thickness, $M=$ Mobility (Pliability) of the mitral valve, $\mathrm{Ca}=$ Calcifications, Sub = Sub valvular apparatus. (") Stroke was the initial presentation; ( $\left.{ }^{\dagger}\right)$ Acceleration time of PR was used to calculate this MPAP, due to inability to record the Doppler signal of the TR. 
Table 3. Pre- and post-PTMC results of mean valve gradient and Mitral valve area in 6 patients and its statistical analysis.

\begin{tabular}{|c|c|c|c|c|}
\hline Patient & Pre-MVG & Post-MVG & Pre-MVA & Post-MVA \\
\hline 1 & 12 & 5 & 0.90 & 1.5 \\
\hline 2 & 19 & 9 & 0.80 & 1.7 \\
\hline 3 & 16 & 6 & 0.78 & 1.4 \\
\hline 4 & 11 & 7 & 1.14 & 1.9 \\
\hline 5 & 13 & 13 & 0.90 & 0.9 \\
\hline 6 & 15 & 10 & 0.90 & 1.6 \\
\hline Mean \pm SD & \multicolumn{2}{|c|}{$6 \pm 3.847$} & \multicolumn{2}{|c|}{$0.596 \pm 0.312$} \\
\hline $95 \% \mathrm{Cl}$ & \multicolumn{2}{|c|}{$(1.9-10)$} & \multicolumn{2}{|c|}{$(.9-1.2)$} \\
\hline$P$ value & \multicolumn{2}{|c|}{0.012} & \multicolumn{2}{|c|}{0.05} \\
\hline
\end{tabular}

MVG = Mean valve gradient; MVA = Mitral valve area

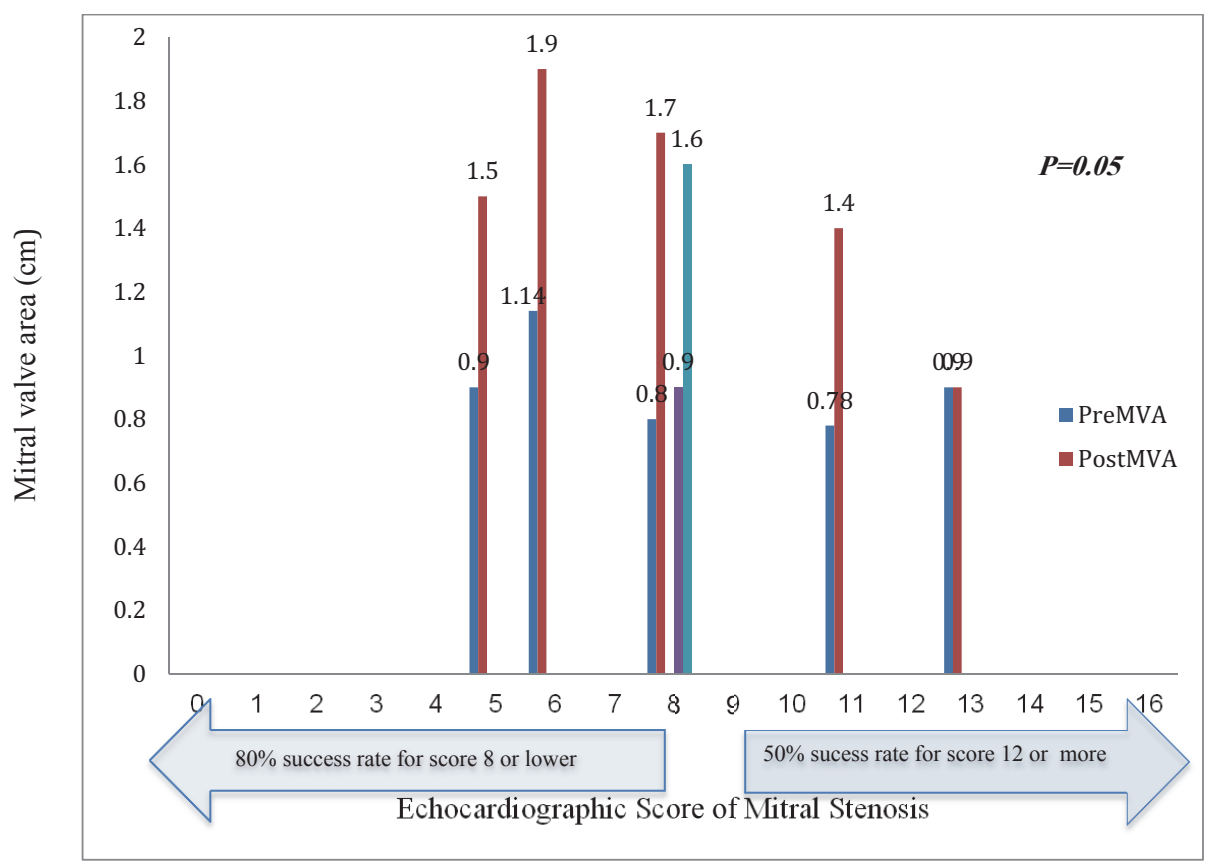

Figure 3. Pre- and post-mitral valve commissurotomy results on mitral valve area (MVA).

the venipuncture site with no more than $1 \mathrm{~g} / \mathrm{dl}$ drop in hemoglobin over 24 hours, no hematoma were reported but ecchymosis was commonly seen. No blood transfusion was reported in any of the cases. One case had a vasovagal attack with quick recovery after intravenous fluid was given. $50 \%$ were discharged the next day; the remaining stayed longer for various reasons, such as optimizing heart failure treatment, and need for diuresis ( 2 cases) or anticoagulation (one case). All patients were discharged on beta-blockers for heart rate control and small dose diuretics. Patients in early 20 s of age were routinely placed on penicillin injection on a monthly basis until the age of 25 , or 10 years from the last documented episode of rheumatic fever ${ }^{[16]}$. The most common laboratory findings on the day after the procedure were mild elevation in white cell counts and cardiac enzymes (Creatine Kinase and Troponin) with variable degree (higher with more serial attempts of balloons inflation and crossing mitral valve orifice).

Despite a good follow-up turnover in the first 6 months to 1 year, there is a significant drop after the first year to more than $50 \%$. None of the subjects have needed a re-ballooning procedure in the span of the 6 years. Two cases had reported mortality both of which were above the age of 45 years; one had severe pulmonary hypertension and refractory heart failure and died within 2 months after procedure, the second one with right dense hemiplegia due to valvular atrial fibrillation died from septic shock and aspiration pneumonia 6 months after PTMC, in both cases PTMC were done successfully. 


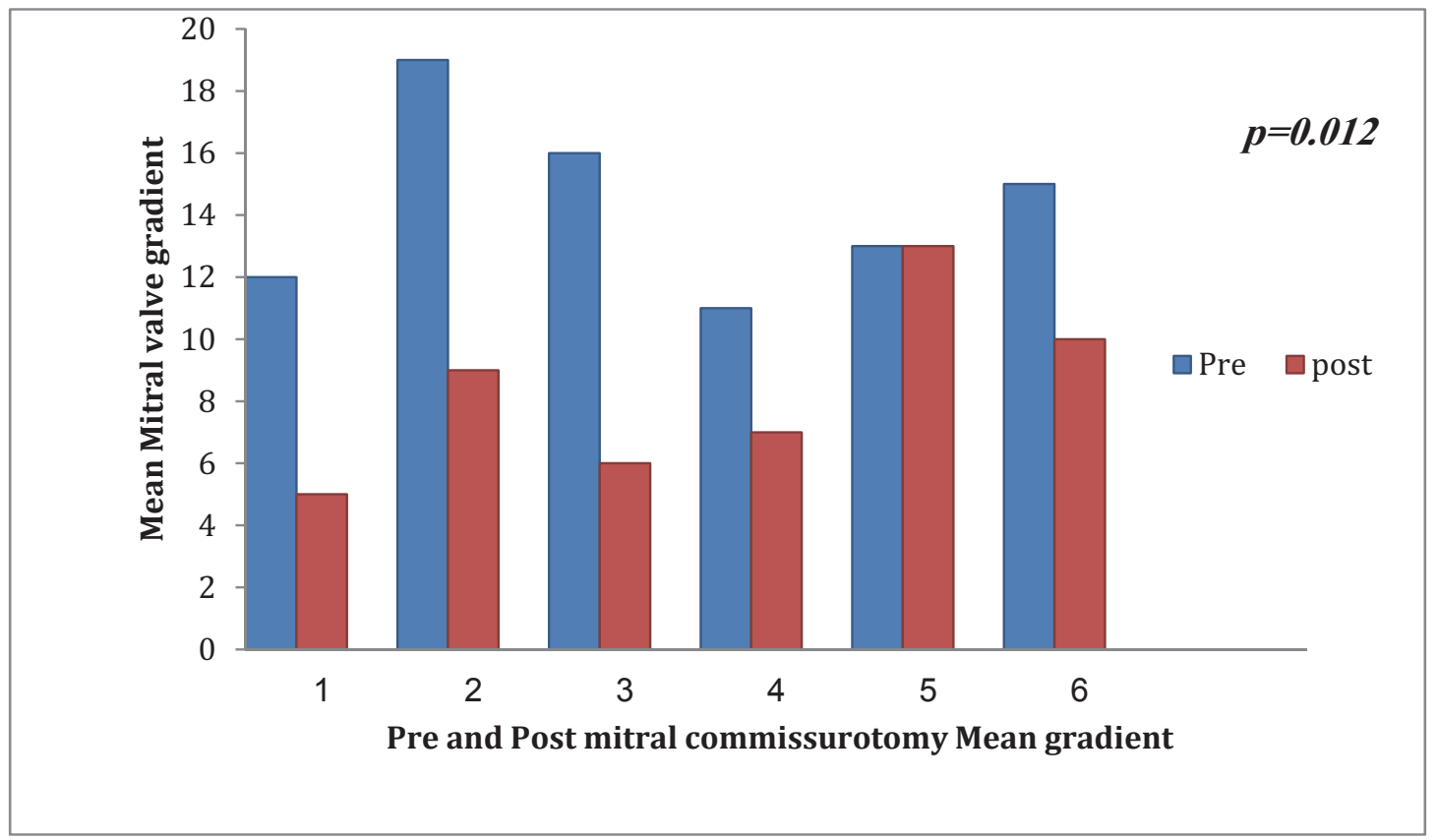

Figure 4. Pre- and post-mitral commissurotomy mean gradient.

\section{Discussions}

Comparing our data to most recently published series from India the success rate was $83 \%$ vs. $93 \%$, average age was 38 versus 32 respectively and rate of atrial fibrillation was $16 \%$ on both series ${ }^{[4]}$. In the six-year follow-up period of our study two deaths occurred and were unrelated to the procedure itself none of the survivors needed re-ballooning, when compared to most recent reports on long-term outcome ${ }^{[42]}$ with a mean follow-up of 13.5 years, (39\%) remained event free, (8\%) died, $8 \%$ required a second PTMC and $43.5 \%$ required surgical intervention. Poor functional status, new onset mitral regurgitation and valve morphology were independent factors of poor prognosis ${ }^{[4]}$. In another contemporary report with a mean followup of 11.6 years both male gender and Wilkins score were additional predictors of poor outcomes, valve area above 1.75 is the best predictor of durability after PTMC ${ }^{[43]}$.

The article describes a real-time experience and true scenarios of some of the challenging cases in a single tertiary center, despite the limited number of cases of rheumatic mitral stenosis ( $\mathrm{R}$ (21 cases). As indicated above, they represent comparable information to what have been reported from other centers with larger volume. The spectrum and complexity of cases are diverse and clinical presentation is rather complex, the series of eligible PTMC cases ( $n$
=6) are limited in number due to several factors, first and foremost is the significant drop in the incidence of rheumatic fever over the last two decades in Saudi Arabia. The second most important factor is advanced stages of mitral stenosis at the time of diagnosis makes intervention with percutaneous approach very limited due to high Wilkins score with extensive calcifications, concomitant mitral regurgitation, presence of coronary artery disease and or other valvular lesions that favor surgical interventions. Finally, referral-related bias; with more complex cases being referred to some centers than others, for example in the city of Jeddah there are more than 9 catheterization laboratories, 5 of which are able to perform PTMC. Albeit fewer in numbers nowadays, operators are more confronted with the complexity of the cases and need for more technical skills to perform PTMC successfully. The rule of ICE or 2/3 D-TEE in these cases is well established as they are both superior to fluoro-guided approach and highly encouraged, ICE is more convenient in PTMC and other structural interventions compared to TEE since no general anesthesia is required and it really helps guiding the directions of the balloon and site of septal puncture particularly in cases with e.g. septal hypertrophy, large left atrium.

Several prognostic factors of outcome like advanced age in addition to pulmonary hypertension, heart failure and stroke have been implicated in the past ${ }^{[15]}$. They are markers of bad outcomes regardless of 
PTMC result. They have to be sought when addressing cases of RMS before considering interventions. In the hands of an experienced interventionist PTMC is effective and durable for symptomatic patients with mitral stenosis with no other significant valve pathology and proper selection criteria.

\section{Conclusions}

Rheumatic mitral stenosis is rarely seen nowadays, due to lower incidence of rheumatic fever and clinical presentation with symptoms tend to be late and with unfavorable anatomy and poor prognostic factors. Despite the limited number of PTMC done in the contemporary era, complexity of cases and technical challenges are greater and require more skills and utilization of technology like ICE or TEE. Age greater than 45 in addition to significant pulmonary hypertension (mean PAP >35), heart failure and stroke are poor prognostic factors despite successful PTMC. PTMC is durable when 4-point echocardiographic score (Wilkin's score) is used and careful selection of patient is ensured.

\section{Acknowledgement}

The author would like to thank Mr. Al Gelanie R. Antonio a research assistant at the Cardiac Unit, King Abdulaziz University Hospital for his support in this study and role to enter patients' data related to initial visits, intervention and post interventional follow-ups

\section{Conflict of Interest}

The author has no conflict of interest.

\section{Disclosure}

The author did not receive any type of commercial support either in forms of compensation or financial for this study. The author has no financial interest in any of the products or devices, or drugs mentioned in this article.

\section{Ethical Approval}

Obtained.

\section{References}

[1] Rose AG. Etiology of valvular heart disease. Curr Opin Cardiol 1996; 11(2): 98-113.

[2] al-Eissa YA. Acute rheumatic fever during childhood in Saudi Arabia. Ann Trop Paediatr: 1991; 11(3): 225-231.
[3] al-Sekait MA, al-Sweliem AA, Tahir M. Rheumatic heart disease in schoolchildren in western district, Saudi Arabia. J R Soc Health 1990; 110(1): 15-16, 19.

[4] Qurashi MA. The pattern of acute rheumatic fever in children: Experience at the children's hospital, Riyadh, Saudi Arabia. J Saudi Heart Assoc 2009; 21(4): 215-220.

[5] Abdul-Mohsen MF, Lardhi AA. A dramatic decline in university hospital admissions of acute rheumatic fever in the eastern region of Saudi Arabia. J Saudi Heart Assoc 2011; 23(2): 87-91.

[6] Miyake CY, Gauvreau K, Tani LY, Sundel RP, Newburger JW. Characteristic of children discharged from hospitals in the United Statesin 2000 with the diagnosis of acute rheumatic fever. Pediatrics 2007; 120(3): 503-508.

[7] Carapetis JR. Rheumatic heart disease in developing countries. N Engl J Med 2007; 357(5): 439-441.

[8] ROWE JC, BLAND EF, SPRAGUE HB, WHITE PD. The course of mitral stenosis without surgery: ten- and twenty-year perspectives. Ann Intern Med 1960; 52: 741-749.

[9] BLAND EF, DUCKETT JONES T. Rheumatic fever and rheumatic heart disease; a twenty year report on 1000 patients followed since childhood. Circulation 1951; 4(6): 836-843.

[10] Meira ZM, Goulart EM, Colosimo EA, Mota CC. Long term follow up of rheumatic fever and predictors of severe rheumatic valvular disease in Brazilian children and adolescents Heart 2005; 91(8): 1019-1022.

[11] Nishimura RA, Otto CM, Bonow RO, Carabello BA, Erwin JP 3rd, Guyton RA, O'Gara PT, Ruiz CE, Skubas NJ, Sorajja P, Sundt TM 3rd, Thomas JD; American College of Cardiology/American Heart Association Task Force on Practice Guidelines. 2014 AHA/ACC guideline for the management of patients with valvular heart disease: a report of the American College of Cardiology/American Heart Association Task Force on Practice Guidelines. J Am Coll Cardiol 2014; 63(22): e57-185.

[12] Inoue K, Owaki T, Nakamura T, Kitamura F, Miyamoto N. Clinical application of transvenous mitral commissurotomy by a new balloon catheter. J Thorac Cardiovasc Surg 1984; 87(3): 394

[13] Wilkins GT, Weyman AE, Abascal VM, Block PC, Palacios IF. Percutaneous balloon dilatation of the mitral valve: an analysis of echocardiographic variables related to outcome and the mechanism of dilatation. Br Heart J 1988; 60(4): 299-308.

[14] Omran AS, Arifi AA, Mohamed AA. Echocardiography in mitral stenosis. J Saudi Heart Assoc 2011; 23(1): 51-58.

[15] Palacios IF, Sanchez PL, Harrell LC, Weyman AE, Block PC. Which patients benefit from percutaneous mitral balloon valvuloplasty? Prevalvuloplasty and postvalvuloplasty variables that predict long-term outcome. Circulation 2002; 105(12): 1465-1471.

[16] Bouleti C, lung B, Himbert D, Brochet E, Messika-Zeitoun D, Détaint D, Garbarz E, Cormier B, Vahanian A. Reinterventions 
after percutaneous mitral commissurotomy during long-term follow-up, up to 20 years: the role of repeat percutaneous mitral commissurotomy. Eur Heart J 2013; 34(25): 1923-1930.

[17] Abbag F, Benjamin B, Kardash MM, Al Barki A. Acute rheumatic fever in southern Saudi Arabia. East Afr Med J 1998; 75(5): 279-281.

[18] Abascal VM, Wilkins GT, O'Shea JP, Choong CY, Palacios IF, Thomas JD, Rosas E, Newell JB, Block PC, Weyman AE. Prediction of successful outcome in 130 patients undergoing percutaneous balloon mitral valvotomy. Circulation 1990; 82(2): 448-456.

[19] Abu-Sabaah AH, Ghazi HO. Better diagnosis and treatment of throat infections caused by group $A$ beta-hemolytic streptococci. Br J Biomed Sci 2006; 63(4); 155-158.

[20] Baumgartber $H$, Hung J, Bermejo J, Evangelista A, Griffin BP, lung B, Otto CM, Pelikka PA, Quiñons M. American Society of Echocardiography; European Association of Echocardiography. Echocardiographic assessment of valve stenosis: EAE/ASE recommendations for clinical practice. J Am Soc Echocardiogr 2009; 22(1): 1-23.

[21] Boudoulas H, Vavuranakis M, Wooley CF. Valvular heart disease: the influence of changing etiology on nosology. J Heart Valve Dis 1994; 3(5): 516-526.

[22] AmericanCollegeofCardiology; American HeartAssociation Task Force on Practice Guidelines (Writing Committee to revise the 1998 guidelines for the management of patients with valvular heart disease); Society of Cardiovascular Anesthesiologists, Bonow RO, Carabello BA, Chatterjee K, de Leon AC Jr, Faxon DP, Freed MD, Gaasch WH, Lytle BW, Nishimura RA, O'Gara PT, O'Rourke RA, Otto CM, Shah PM, Shanewise JS, Smith SC Jr, Jacobs AK, Adams CD, Anderson JL, Antman EM, Fuster V, Halperin JL, Hiratzka LF, Hunt SA, Lytle BW, Nishimura R, Page RL, Riegel B. ACC/ AHA guidelines for the management of patients with valvular heart disease. A report of the American College of Cardiology/American Heart Association Task Force on Practice Guidelines (Writing committee to revise the 1998 guidelines for the management of patients with valvular heart disease). J Am Coll Cardiol 2006; 48(3): e1-148.

[23] Carapetis JR, Steer AC, Mulholland EK, Weber M. The global burden of group A streptococcal diseases. Lancet Infect Dis 2005; 5(11): 685-694.

[24] Carapetis JR, Mayosi BM, Kaplan EL. Controlling rheumatic heart disease in developing countries. Cardiovasc J S Afr 2006; 17(4): 164-165.

[25] Carroll JD, Feldman T. Percutaneous mitral balloon valvotomy and the new demographics of mitral stenosis. JAMA 1993; 270(14): 1731-1736.

[26] Chagani HS, Aziz K. Clinical profile of acute rheumatic fever in Pakistan. Cardiol Young 2003; 13(1): 28-35.

[27] Garber M A, Baltimore RS, Eatoc CB, Gewitz M, Rowley $\mathrm{AH}$, Shulman ST, Taubert ST. Prevention of rheumatic fever and diagnosis and treatment of acute Streptococcal pharyngitis: a scientific statement from the American Heart
Association Rheumatic Fever, Endocarditis, and Kawasaki Disease Committee of the Council on Cardiovascular Disease in the Young, the Interdisciplinary Council on Functional Genomics and Translational Biology, and the Interdisciplinary Council on Quality of Care and Outcomes Research: endorsed by the American Academy of Pediatrics. Circulation 2009; 119(11): 1541-1551.

[28] Green NE, Hansgen AR, Carroll JD. Initial clinical experience with intracardiac echocardiography in guiding balloon mitral valvuloplasty: technique, safety, utility, and limitations. Catheter Cardiovasc Interv 2004; 63(3): 385394.

[29] Kronzon I, Tunick PA, Schwinger ME, Slater J, Glassman E. Transesophageal echocardiography during percutaneous mitral valvuloplasty. J Am Soc Echocardiogr 1989; 2(6): 380-385.

[30] Lock JE, Khalilullah M, Shrivastava S, Bahl V, Kaene JF. Percutaneous catheter commissurotomy in rheumatic mitral stenosis. N Engl J Med 1985; 313(24): 1515-1518.

[31] Lokhandwala YY, Banker D, Vora AM. Kerkar PG, Deshpande JR, Kulkarni HL, Dalvi BV. Emergent balloon mitral valvotomy in patients presenting with cardiac arrest, cardiogenic shock or refractory pulmonary edema. J Am Coll Cardiol 1998; 32(1): 154-158.

[32] lung B, Cormier B, Ducimetière P, Porte JM, Nallet O, Michel $\mathrm{PL}$, Acar J, Vahanian A. Immediate result of percutaneous mitral commissurotomy. A predictive model on a series of 1514 patients. Circulation 1996; 94(9): 2124-2130.

[33] Marijon E, Ou P, Celermajer DS, Ferreira B, Mocumbi AO, Sidi $D$, Jouven X. Echocardiographic screening for rheumatic heart disease. Bull World Health Organ 2008; 86(2): 84.

[34] Meneveau N, Schiele F, Seronde MF. Breton V, Gupta S, Bernard Y, Bassand JP. Predictors of event-free survival after percutaneous mitral commissurotomy. Heart 1998; 80(4): 359-364.

[35] Reményi B, Wilson N, Steer A, Ferreira B, Kado J, Kumar K, Lawrenson J, Maguire G, Marijon E, Mirabel M, Mocumbi AO, Mota C, Paar J, Saxena A, Scheel J, Stirling J, Viali S, Balekundri VI, Wheaton G, Zühlke L, Carapetis J. Word Heart Federation criteria for echocardiographic diagnosis of rheumatic heart disease--an evidence-based guideline. Nat Rev Cardiol 2012; 9(5): 297

[36] Sliwa K, Carrington M, Mayosi BM, Zigiriadis E, Mvungi R, Stewart S. Incidence and characteristics of newly diagnosed rheumatic heart disease in urban African adults: insights from the heart of Soweto study. Eur Heart J 2010; 31(6): 719-727.

[37] Strasser T, Dondog N, El Kholy A, Gharagozloo R, Kalbian W, Ogunbi O, Padmavati S, Stuart K, Dowd E, Bekeesy A. The community control of rheumatic fever and rheumatic heart disease: report of a WHO international cooperative project. Bull World Health Organ 1981; 59(2): 285294.

[38] Stefanadis Cl, Stratos CG, Lambrou SG, BahI VK, Cokkinos DV, Voudris VA, Foussas SG,Tsiofis CP, Toutouza PK. Retrograde nontransseptal balloon mitral valvuloplasty: immediate 
Percutaneous Trans-Mitral Commissurotomy in the Contemporary Era, Real Time Experience and a Retrospective Analysis W.A. Alhejily

results and intermediate long-term outcome in 441 cases-a multicenter experience. J Am Coll Cardiol 1998; 32(4): 1009-1016.

[39] Sutaria N, Northridge DB, Shaw TR. Significance of commissural calcification on outcome of mitral balloon valvotomy. Heart 2000; 84(4): 398-402.

[40] [No authors listed]. Rheumatic fever and rheumatic heart disease. World Health Organ Tech Rep Ser 2004; 923: 1-122.

[41] Sharma J, Goel PK, Pandey CM, Awashi A, Kapoor A, Tewari S, Garg N, Kumar S, Khanna R. Intermediate outcomes of rheumatic mitral stenosis post-balloon valvotomy. Asian Cardiovasc Thorac Ann 2015; 23(8): 923-930.

[42] Martínez RG, Fajuri NA, Córdova AS, Braun JS, Marchant DE, Guarda SE, Veas PN, Méndez LM, Lindefjeld CD, Pérez PO, Flores A, Valenzuela E, Martínez SA. [Long Term results of mitral balloon valvuloplasty]. Rev Med Chil 2014; 142(11): 1363-1370.

[43] Tomai F, Gaspardone A, Versaci F, Ghini AS, Altamura L, De Luca L, Gioffrè G, Gioffrè PA. Twenty year follow-up after successful percutaneous balloon mitral valvuloplasty in a large contemporary series of patients with mitral stenosis. Int J Cardiol 2014; 177(3): 881-885. 
علاج ضيق الصمام الميترالي بالقسطرة العلاجية في الوقت المعاصر، الخبرة الحالية وتحليل نتائجها

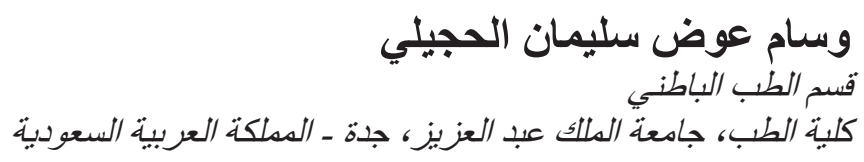

المستخطص. ض ضيق الصمام الميتر الي الناتج عن الحمى الروماتيزمية نادر الحدوث في الوقت المعاصر. في المملكة العربية

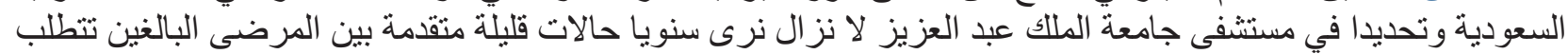

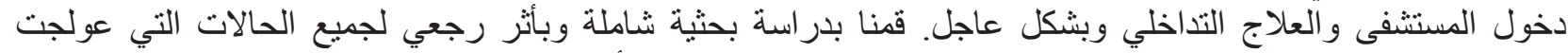

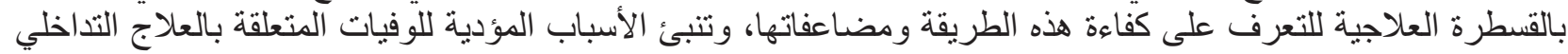

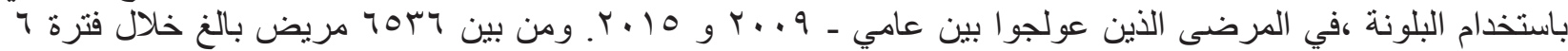

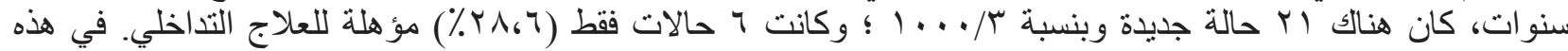

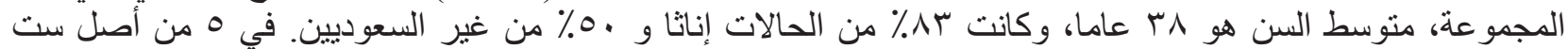

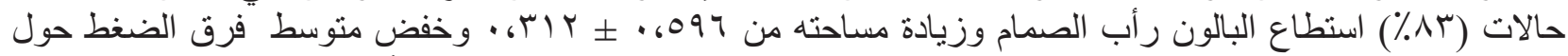

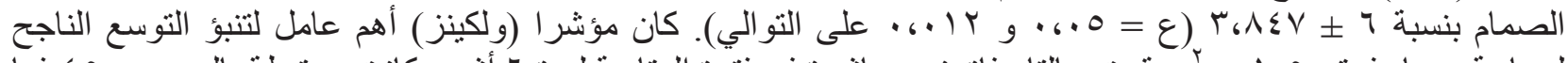

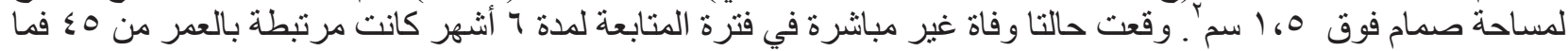

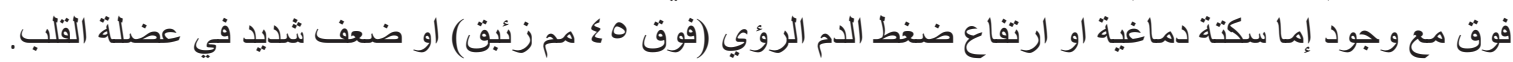

